\title{
Knowledge Management in Set Based Lean Product Development Process
}

\author{
Robert Furian ${ }^{1}$, Frank von Lacroix ${ }^{1}$, Dragan Stokic $^{2}$, Ana Correia ${ }^{2}$, Cristina Grama ${ }^{2}$, \\ Stefan Faltus ${ }^{2}$, Maksim Maksimovic ${ }^{3}$, Karl-Heinrich Grote ${ }^{4}$, and Christiane Beyer ${ }^{5}$ \\ ${ }^{1}$ Volkswagen AG, Wolfsburg, Germany \\ \{robert. furian, frank. lacroix\}@volkswagen. de \\ ${ }^{2}$ Institut für angewandte Systemtechnik Bremen, Germany \\ \{dragan, correia, grama, faltus\} aatb-bremen. de \\ ${ }^{3}$ Cranfield University, United Kingdom \\ m.maksimovic@cranfield.ac.uk \\ ${ }^{4}$ Otto-von-Guericke-Universität Magdeburg, Germany \\ karl.grote@ovgu.de \\ ${ }^{5}$ California State University, Long Beach, USA \\ cbeyer@csulb.edu
}

\begin{abstract}
The objective of the research is to examine and develop new methods and tools for management of knowledge in Lean Product development. Lean Product development attempts to apply lean philosophy and principles within product development process. Special emphasis is given to the so-called Set Based Lean Design principles. Such product development process requires innovative methodologies and tools for capturing, reuse and provision of knowledge needed for decision making, as well as advanced ICT environment for Knowledge Management (KM).

A Set Based Lean Design toolkit is developed, aiming to support the product developer in making decisions during the development process. This toolkit includes the Lean Knowledge Life Cycle methodology and a set of software tools for KM. The application of the methods and tools is investigated within large automotive industry and its supplier.
\end{abstract}

Keywords: Knowledge management, knowledge based environment, product development process, LeanPPD, Lean development.

\section{$1 \quad$ Introduction}

In modern manufacturing industry, such as automotive industry, shorter product life cycles and strong competition demand more efficiency in the product development process. Therefore, the product models have to be adapted to the particular market requirements and have to be released fast and cost-efficiently on the markets. However, the product development costs are increasing because of rising diversity of models, fast technology progress and incremental complexity of the automobile [1].

Lean development transforms the philosophy of lean thinking into the product development and the product emerge process. The identification and reduction of 
wastes and the boosting of value adding is much more complicated in development because of unique and new project themes with innovative character and development cycles of often about several years. This is contrary to the production, where always similar products in short cycles are produced in exactly defined process chains [2].

In [3] a new paradigm - Lean Product development - is proposed, which takes the lean thinking from waste elimination into value creation. The aim of the research is to develop a comprehensive set of lean methods, methodologies, design techniques and tools to ensure the development of lean product design. Special emphasis is given to the Set Based Design principles. Set Based Lean Design (SBLD) is a methodology similar to DFx and DFMA (Design for Manufacturing and Assembly) [4]. SBLD supports the generation of lean product design and its simultaneous consideration of lean manufacturing required for the physical realization of the product. The following main aspects have to be implemented to the SBLD [3]:

- A method to capture the customer values into a set of designs

- A mechanism to break down these sets to get an optimized final lean design

- The identification of features and tools of the key product

Knowledge reuse is one of the most important factors in increasing efficiency in product development and one of the key factors of the proposed Lean product development. However, due to the inherently unstructured form of knowledge, currently there are obstacles to finding the right knowledge at the right time. In this paper a Knowledge Based Environment (KBE) is proposed, supporting Set Based Lean Product development process, including support for knowledge acquisition and structuring, as well as timely and efficient re-use of previously acquired knowledge. Especially in very large Extended Enterprises, such as the ones typical of the automotive industry, where the knowledge and expertise of a variety of people needs to be used efficiently, such an approach is expected to lead to big improvements in knowledge management. This KBE is the main source of knowledge, from which a set of new designs for a new product is going to be defined [3].

The paper presents a Set Based Lean Design toolkit developed, aiming to support the product developer in making decisions during the development process. This toolkit includes the Lean Knowledge Life Cycle methodology and a set of software tools for KM.

The toolkit is under testing within the Volkswagen Group, which is one of the world's leading automobile manufacturers and the largest car maker in Europe. The toolkit and concepts of Lean Product Development and KBE will the transferred, implemented, tested and evaluated in a development department in the component division of Volkswagen to support the knowledge management in product development and support the product designers in decision making.

\section{Lean Knowledge Life Cycle}

The Lean Knowledge Life Cycle (LeanKLC), developed by [5], was defined as an outcome of the LeanPPD project and provides a methodology for knowledge capture, 
re-use and creation in product development. The significance of Knowledge is well recognized in the Lean Product Development literature [6, 7, 8, 9, 10, 11]. However, it was observed that current knowledge life cycles methodologies, such as $[12,13,14$, 15], lack supporting tools to be integrated in product development activities in order to provide a Knowledge based environment, which is an important element in LeanPPD [15]. The LeanKLC is addressing both the previous project, as well as the domain knowledge in product development. The LeanKLC follows a sequence of seven stages:

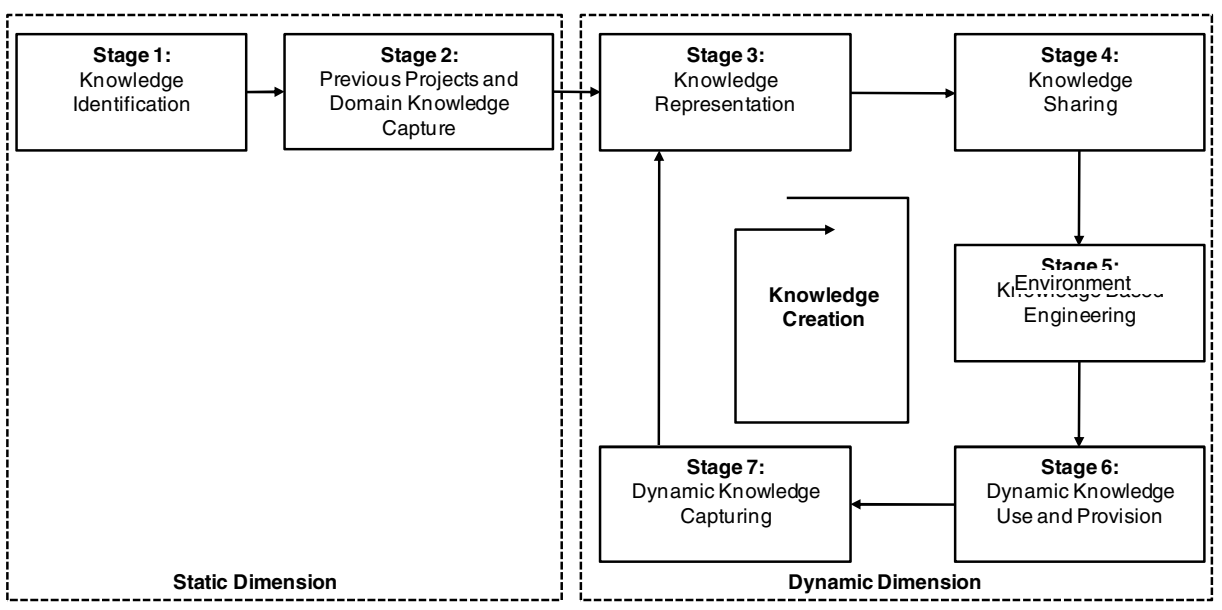

Fig. 1. Lean Knowledge Life Cycle [5]

In the first stage, the knowledge relevant in the product development process has to be found and identified. This knowledge is captured and structured in the second phase and categorized into knowledge from previous projects, like lessons learned, or into domain specific knowledge, e.g. design rules. In the next stage, the knowledge has to be represented in a generic way (e.g. OWL) in order to make it usable for ICT tools (e.g. Protégé). The fourth stage is the sharing of knowledge, which requires the storage in a centralized database with a clear structure, before getting implemented in the fifth step in the knowledge based environment (KBE). In the sixth step the knowledge from the $\mathrm{KBE}$ is dynamically used and provided to the product development engineers. In the seventh and final stage engineers will dynamically capture new knowledge already while it is created. The previously described stages require different practices, tools and templates, which are currently under development in cooperation with industrial partners within the LeanPPD project and envisioned to be tested in different business cases [5].

\section{Knowledge Management Software Tool}

The analysis of the existing ICT tools indicated that there are no specific SW tools to support Set Based Lean Design. 'Conventional' ICT tools for 'classical' design can 
(and are) used to support set based design. However, a clear need is identified to develop innovative tools specifically aiming to support KM for SBLD during various phases of the development process.

\subsection{Requirements}

Working as a development engineer in the automotive industry often means working in teams on different parts. Keeping an eye on design changes which have an impact on the design of related parts can lead to a lot of extra work. Especially in set-based design, it is even more complex since the number of possible designs grows significantly with an increasing number of parts sets and parallel designs. The main requirements of the knowledge management software tool, identified by several large industrial companies, are [5]:

- Support knowledge management, i.e. management of product data/ knowledge for SBCE, for different sets of solutions, provision of design rules, including lean design rules

- Decision making support tools, specifically decisions regarding costs, i.e. tool to explore system sets and evaluate sets for lean production

- Support the re-use of existing designs (sets of solutions), e.g. from previous projects/designs

\subsection{Implementation of the SW Tool}

In order to support the handling of set-based design, based on the above described requirements, a SW tool was implemented to help engineers with the set-based design method. The detailed functions of the tool, for use in product development, were defined by the following:

- Management of parallel design sets: different part sets management with support for set-based lean design

- Part history: documentation of the complete "evolution" of the part, including the management of parallel designs in the different design phases of the part and visualization how the part looked before the change and after the change

- Support in provision of knowledge (rules) including lean design rules

- Support in acquisition of knowledge and report creation including the requests of changes in designs as well as the reasons for accepted and rejected requests

- Re-use of knowledge from previous projects and design-sets

- Support of collaborative work to make department specific knowledge about the requested changes available across all involved departments and automatically inform them about design changes and request their feedback

- Enable search with semantic indexing of keywords to find the knowledge from previous projects 
The key concept of the tool is presented in Fig. 2. The tool can be applied at various stages of product development - at system level (whole product) or component level. Its current implementation is focused on a component level, assuming that the SBLD might be applied also at the whole product level. The tool intends to support set based design of components supporting the management of knowledge for sets of design, relations between options etc.

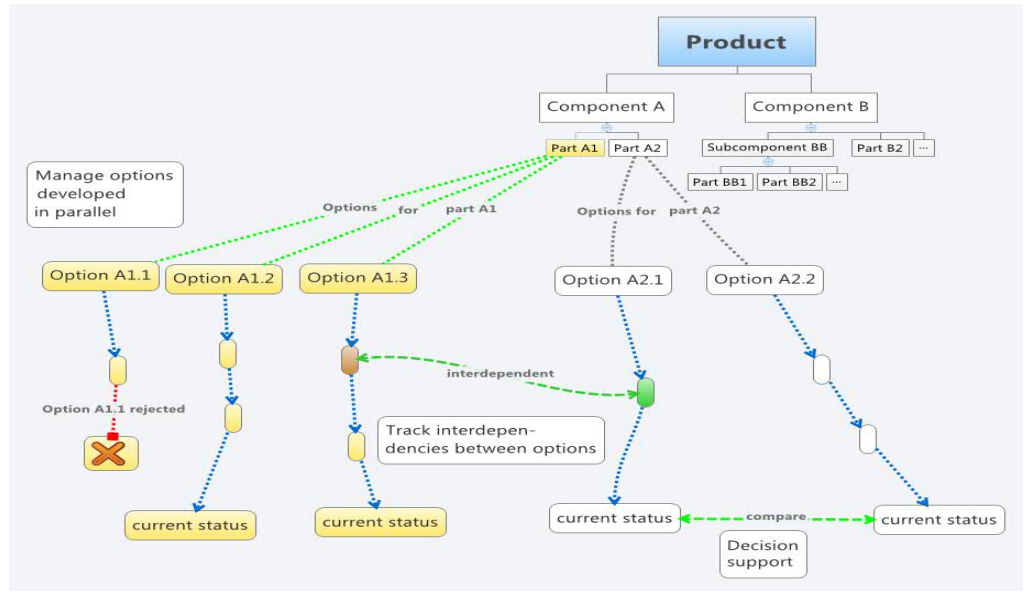

Fig. 2. Concept of the SBLD Product Data/Knowledge Management Tool

As mentioned before, the main task of the tool is to help the designer in the management of the sets of design of parts and components. In product development, changes to assemblies and parts have to be done to increase customer value but they also have impact on the shape and function of their nearby assemblies and parts.

The knowledge management tool is easy to integrate in the product development process and can be used during different stages within it:

- In the concept phase where different sets of design have to be evaluated

- In the construction phase of the part, where the 3D-CAD-model and the part list is created

- In the tooling, prototyping and testing phase, where changes from the tool shop and testing have to be implemented in the CAD-drawings

It also provides design knowledge, e.g. design rules of welding plastics or metals, directly to the product developer.

In the module which shows history of the part ("evolution"), the SW tool allows to automatically create reports which contain all changes which have been applied on the part as well as all general information about the part itself. Since design changes result in higher project costs from a certain stage of the project, the SW tool allows to create reports, describing the change, which will be distributed among all involved engineers and departments (planning, tool shop, finances, etc.) to support the decision 
making if a certain change in the design is necessary or not. Each involved engineer / department can use the SW tool to approve or disapprove the change in the design.

Before the final request to change the design of the part, which has impact on other departments like the planning department or the tool shop, the SW tool supports the designer in providing information about previous or parallel projects which have a similar focus. This provision of knowledge from previous projects and other relevant topics is realized by suggesting other reports, design rules or related projects of possible interest. The SW tool retrieves those documents by querying a search engine whose index is built by an indexing engine (see 3.3). This indexing engine works in the background and automatically indexes all reports and design change requests that are added to the database of the SW tool. No matter if the change in the design of part is applied or not, the new knowledge about this change is annotated and added to the database. In case of rejection, the cause is also annotated and added to prevent other designers from requesting the same change again.

Furthermore a tag cloud showing the most associated keywords to this part allows the designer to directly switch to the related domain knowledge where design and construction knowledge can be obtained.

\subsection{Knowledge Search Engine and Ontological Structure}

The tool provides a special search mechanism to easily find knowledge from previous projects, which includes search by product \& part, search by project phase/ date, free text search etc. Furthermore, this can be used to find design rules which are related to the parts and in this way support users in applying lean manufacturing principles.

The approach is to combine the knowledge management tool with an ontological based structuring of data/knowledge for context sensitive enhancement, where product and process knowledge is stored. This ontology is also used to store all extracted context for future reuse. The process is supported by modular services which allow docking onto different systems to monitor and analyze user's interactions and support subsequent services (Context Extraction and Knowledge Search) through monitoring data.

The search is therefore divided into several sub-services. These are:

- Knowledge Monitoring and Indexing

- Context Extraction and Context Model

- Search User Interface

The knowledge monitoring is used to monitor human-computer-interaction in order to extract the actual context to further enhance it with according knowledge. For that, user interaction is being closely monitored, "raw data" collected and enriched with available knowledge. At significantly changed circumstances in the context, configurable defined, all gathered data is forwarded to context extraction services to extract actual context. In a search application, the objective of such monitoring services is to observe user interactions in order to enable context extraction and knowledge enhancing services to provide assistance in refining the search query. In providing e.g. keywords that have been used in similar situations or filter allowing to 
narrow down search results in an appropriate thematically way, the user is contextually supported in his current situation. Beside the monitored situations, this service also persist meta-information about the knowledge-items which are associated with monitored events. This data is extracted by an appropriate parser and analyser of the Knowledge Monitoring and Indexing services and stored into a Lucene-Index to allow a fast and efficient reuse [17]. Knowledge Items to be index for reuse may reside in any external system, which offers an interface to the outside (e.g. file system, database or WIKI).

To enhance application functionality, monitoring services are monitoring states and conditions in order to trigger other services, for instance "auto-completion services" to give instantaneous feedback to the user during text input. To accomplish that, a monitoring service observes a text box, forwarding text input to a backend service for further processing. This approach enables direct feedback and does not require the user to explicitly trigger the service (e.g. by clicking a button). The overall structure to comprehend the described solution is a Service-oriented Monitoring Architecture (SoMA) within Networked Enterprises [18].

In the product development the use of the search engine and the ontology results in a faster access to information and knowledge that helps the designer in his work. He can faster find structured knowledge from previous projects and search for lean design rules and construction criteria regarding the component he is working on.

\section{Conclusion}

The paper describes a SBLD toolkit developed, aiming to support the product developer in making decisions during the development process. The emphasis is put upon the requirements and the implementation of a knowledge management software tool, which is applied in product development to support SBLD. It is a part of a knowledge based environment and provides set-based lean design rules and domain and specific knowledge to the product designer. This results in a better knowledge management, decision support and communication in product design. Less improvement- and optimization loops are needed because the developer now gets the support of the knowledge management tool. This can save development costs and time in the product development process. The application of the methods and tools is investigated within Volkswagen and its suppliers.

Acknowledgments. The work presented is partly carried out in the scope of the current RTD project LeanPPD supported by the Commission of European Community, under NMP - Nanosciences, Nanotechnologies, Materials and new Production Technologies Program under the contract NMP-2008- 214090. This document does not represent the opinion of the European Community, and the European Community is not responsible for any use that might be made of its content. 


\section{References}

1. Pahl, G., Beitz, W., Feldhusen, J., Grote, K.-H.: Konstruktionslehre - Grundlagen erfolgreicher Produktentwicklung; Methoden und Anwendung, 7. Auflage. Springer, Berlin (2007)

2. Schuh, G., et al.: Lean Innovation - Ein Widerspruch in sich? In: Hacklin, F., Marxt, C. (eds.) Business Excellence in Technologieorientierten Unternehmen, pp. 13-20. Springer, Berlin (2008)

3. Al-Ashaab, A., Shehab, E., Alam, R., Sopelana, A., Sorli, M., Flores, M., Taisch, M., Stokic, D., James-Moore, M.: The Conceptual LeanPPD Model. In: New World Situation: New Directions in Concurrent Engineering, Part 5, pp. 339-346. Springer, London (2010)

4. Huthwaite, B.: The Lean Design Solution. Institute for Lean Design, Mackinac Island (2004)

5. Maksimovic, M., Al-Ashaab, A., Shehab, E., Sulowski, R.: A Lean Knowledge Life Cycle Methodology in Product Development. In: 8th International Conference on Intellectual Capital, Knowledge Management \& Organizational Learning - ICICKM, Bangkok, Thailand (2011)

6. Morgan, J.M., Liker, J.K.: The Toyota Product Development System: Integrating People, Process, and Technology. Productivity Press, New York (2006)

7. Kennedy, M., Harmon, K., Minnock, E.: Ready, Set, Dominate: Implement Toyota's SetBased Learning for Developing Products. The Oakley Press (2008)

8. Sobek II, D.K., Ward, A.C., Liker, J.K.: Toyota's Principles of Set-Based Concurrent Engineering. Sloan Management Review 40(2), 67-83 (1999)

9. Ward, A.C.: Lean Product and Process Development. Lean Enterprises Inst. Inc. (2007)

10. Mascitelli, R.: The Lean Product Development Guidebook: Everything your design team needs to improve efficiency and slash time-to-market. Technology Perspectives (2006)

11. Oosterwal, D.P.: The Lean Machine: How Harley-Davidson drove top-line growth and profitability with revolutionary lean product development. AMACOM/American Management Association (2010)

12. Bukowitz, W.R., Williams, R.L.: Knowledge Management Fieldbook. Prentice-Hall/FT Management, London (1999)

13. Dalkir, K.: Knowledge management in theory and practice. Butterworth-Heinemann (2005)

14. Firestone, J.M., McElroy, M.W.: Key issues in the new knowledge management. Butterworth-Heinemann (2003)

15. Jashapara, A.: Knowledge Management: An integrated approach. Pearson Education (2004)

16. Al-Ashaab, A., Flores, M., Khan, M., Maksimovic, M., Alam, R., Shehab, E., Doultsinou, A., Sopelana, A.: The Industrial requirements of KBE for the LeanPPD model. In: International Conference on Advances in Production Management Systems (APMS 2010), Cernobbio, Lake Como, October 11-13 (2010)

17. Apache Lucene Search Engine, http: / / I ucene. apache. org

18. Ziplies, S., Scholze, S., Stokic, D., Krone, K.: Service-based Knowledge Monitoring of Collaborative Environments for User-context Sensitive Enhancement. In: Proceedings of the 15th International Conference on Concurrent Enterprising, Leiden, Netherlands (2009) 